\title{
INFORME
}

\section{Homenaje a Manuel Mamani Mamani Exmiembro del Comité Editorial y miembro del Comité de Honor
de la Revista Musical Chilena. Universidad de Tarapacá, Arica}

\author{
por \\ Lina Barrientos Pacheco \\ Universidad de La Serena, Chile \\ lbarrien@userena.cl
}

Durante la semana comprendida entre los días 24 y 29 de noviembre de 2014, la Universidad de Tarapacá de Arica, con la colaboración de la Ilustre Municipalidad de Arica y de Putre, la Dirección Regional del Consejo Nacional de la Cultura y las Artes (CNCA), la Corporación Nacional de Desarrollo Indígena (CONADI) y la Fundación Altiplano, realizó un Homenaje en vida al académico aymara Manuel Mamani Mamani por sus más de 45 años de labor docente en la formación de profesores de música y otras disciplinas, la dirección del Ballet Folclórico BAFUT y por sus investigaciones y publicaciones en torno a la música andina de las regiones de Tarapacá y Arica y Parinacota.

Fue un encuentro internacional con invitados de Argentina, Bolivia, México, Perú y destacados estudiosos de manifestaciones de la cultura andina chilena venidos desde Santiago, La Serena, Iquique y Arica propiamente tal. Las actividades estuvieron llenas de música, danza y ritualidad. Contemplaron la visita al Marka Guallatire y al Ayllu Ungallire, lugar de nacimiento del profesor Mamani, un caserío ubicado a orillas de un bofedal del altiplano a más de 4300 metros sobre el nivel del mar; el lanzamiento de su último libro; visitas al Museo de Azapa y Momias Chinchorro y un seminario internacional "Un legado que traspasa fronteras". Finalizó con una gala en el Teatro Municipal de Arica, en la que fueron proyectados los saludos de diversas personalidades que no pudieron asistir, entre ellas la del Dr. Luis Merino Montero, en su calidad de Director de la Revista Musical Chilena, la que fue grabada por Samuel Morales, organizador general del evento, en una visita que le hiciera en Santiago.

Fui invitada por los organizadores a participar de esta conmemoración, en forma especial como expositora en el seminario, en representación del Comité Editorial de la Revista Musical Chilena y como integrante del GEMAndina, Grupo de Estudio de Música Andina de la Universidad de La Serena. El seminario internacional fue una actividad académica que contó con expositores de México, Bolivia y académicos de las Universidades de Tarapacá, Arturo Prat y La Serena, más la Directora del Ballet Folklórico Nacional (BAFONA). Se presentaron un total de nueve ponencias durante toda la mañana del miércoles 27 de noviembre en el Aula Magna de la Universidad de Tarapacá. El seminario tuvo como objetivo dar a conocer los diferentes campos de investigación que Manuel Mamani ha abordado vistos desde las experiencias de otros investigadores. Se analizaron 
sus aportes al patrimonio intangible de nuestra cultura andina chilena y latinoamericana, a la enseñanza de la lengua aymara, a la educación en general y a la pedagogía intercultural. En este contexto presenté una ponencia relativa a sus aportes a la etnomusicología chilena y a la Revista Musical Chilena.

\section{MANUEL MAMANI MAMANI: ETNOMUSICOLOGÍA DESCOLONIZADA Y SU APORTE A LA REVISTA MUSICAL CHILENA.}

\section{Etnomusicología como disciplina}

La etnomusicología es una disciplina científica que busca dar explicaciones a fenómenos relacionados con lo sonoro-musical. Comprende, en lo genérico, el estudio de la música con relación al contexto en que esta es practicada, lo que permite comprender tanto aspectos musicales como culturales, es decir, conductas y comportamientos humanos de una red cerrada de conversaciones (Maturana 2003). En ocasiones el énfasis es puesto en los parámetros musicales y en otras, el énfasis es puesto en la cultura en que se dan las prácticas musicales. Desde ahí han sido planteadas discusiones que permiten delimitar el borde entre la etnomusicología y la antropología de la música, quedando dos enfoques históricos: estudio de la música en la cultura o estudio de la música como cultura (Myers 1992/2001). Es una disciplina originada en la academia europea; el objeto de estudio en sus orígenes fueron las músicas de las otras culturas, las no europeas. Posteriormente se agregaron las músicas de tradición oral, incluyendo las europeas. No obstante en estas tres últimas décadas se abrió el campo de estudio, para incluir los estudios de música popular.

En lo referido a lo epistemológico, aportan a la etnomusicología entrecruzamientos desde el componente arte, por la música; de las humanidades, para explicar cosmovisiones; de las ciencias sociales, por lo etnográfico y antropológico, y por las ciencias fácticas, la físicaacústica aplicada a la organología, entre otros aspectos. En el quehacer etnomusicológico el trabajo de campo es esencial, lo que implica un amplio manejo informativo del contexto en que el estudio musical será realizado, como también el uso de técnicas etnográficas que garanticen una buena recopilación. Es fundamental el rapport para establecer un vínculo de confianza entre el etnomusicólogo y sus colaboradores, incluida una comunidad toda, si fuere el caso.

Otro componente relevante es el trabajo de laboratorio o gabinete, espacio en que es estudiado todo lo recopilado, incluyendo transcripciones y análisis de lo observado y registrado. De acuerdo con mi experiencia es un momento muy delicado, pues aquí aparecen las explicaciones y resultados a las preguntas de investigación, correspondiendo a la interpretación que hace el etnomusicólogo, que plasma en un discurso que habla del otro/ otra, de sus conductas o comportamientos culturales, mirados, como en muchas ocasiones ha ocurrido, desde otra cultura, desde otra red cerrada de conversaciones, que es la propia cultura del investigador, la que conlleva cosmovisiones distintas e implica incluso lenguas diferentes. Reconocemos que esta fue la perspectiva originaria de la etnomusicología, como por ejemplo la elaboración de una variedad de discursos que explican la práctica musical andina y su contexto desde la cultura occidental europea.

\section{Algunos antecedentes históricos}

Fue el vienés Guido Adler, quien en 1885 realizó una publicación en la que hace referencia al estudio de músicas de otras culturas (no europeas) con fines etnográficos, basados principalmente en canciones folclóricas. En esta primera etapa la disciplina recibió el 
nombre de "musicología comparada", la que además contó con ayuda tecnológica, gracias a la invención del fonógrafo por Thomas Edison en 1877. Esto permitió grabar melodías en cilindros de cera para posteriormente transcribirlas, analizarlas y realizar estudios comparativos de esas músicas, teniendo como referente la construcción teórica de la música docta o académica europea.

Con el pasar del tiempo, el término "musicología comparada" fue poco a poco revisado. La disciplina pasó a ser nominada definitivamente "etno-musicología" a partir de mediados de los años cincuenta. Esto llevó a europeos y estadounidenses que investigaban a redefinir el campo y el objeto de estudio, junto a los métodos y las técnicas que les indicaran el camino a seguir. Estos resultados fueron producto de las propias experiencias acumuladas en el desarrollo de la disciplina por la ejecución de proyectos concretos, en que el trabajo de campo fue, y como lo sigue siendo en la actualidad, primordial. Posteriormente a esta época fueron elaboradas diversas distinciones y definiciones sobre el quehacer etnomusicológico. Asimismo, fueron creadas sociedades que aglutinaban a estos etnomusicólogos, junto a revistas científicas y centros o unidades académicas en universidades que impartieron la formación profesional de etnomusicólogos.

La escuela estadounidense de la UCLA (Universidad de California, Los Ángeles) contribuyó al surgimiento y desarrollo de la etnomusicología en Chile, por medio de María Ester Grebe Vicuña. Al reincorporarse a la entonces Facultad de Ciencias y Artes Musicales y de la Representación de la Universidad de Chile, después de una estadía en Los Angeles, interviene en 1971 el currículo que se ofrecía entonces en la carrera de pedagogía en educación musical con la asignatura "Introducción a la etnomusicología", dictada en paralelo a "Folclore musical" impartida entonces por Raquel Barros. Con el ímpetu que la caracterizaba y su rigurosidad académica, logró en 1973 que se abriera la carrera de Etnomusicología, siendo parte de este linaje mi propia formación. Sin embargo, esta propuesta se sustentaba en el enfoque positivista-europeizante, que consideraba al "otro" como "informante" y como objeto de estudio. Tanto la mirada del investigador, sus métodos, como los resultados de sus estudios, eran considerados caminos explicativos "objetivos", datos "neutrales", capaces de constituir leyes generales de conductas musicales de una cultura determinada.

\section{Etnomusicología: posmodernidad-poscolonialidad-descolonización}

Con el paso del tiempo acaecieron diversos sucesos y personalidades de las disciplinas humanistas y de las ciencias sociales. Sus aportes echaron abajo las premisas anteriormente enunciadas. Apareció un modo de realizar estudios etnomusicológicos bajo otros paradigmas, en un medio distinguido como posmodernidad, acompañado de discursos en que prevalecen lo local y lo particular, que favorecen posiciones de pluralidad y diferencia y que valoran las diferencias de género, edades y etnias (Pelinski 2000). De similar manera ha sido reformulada la etnografía musical, la que considera que "pasar del estudio de la música como objeto al estudio de la música como cultura lleva a practicar una etnomusicología reflexiva en la cual el investigador no puede situarse fuera de la cultura como observador de una cultura objetivamente observable ...la subjetividad del investigador interfiere en el proceso de su experiencia de la cultura estudiada (vivida)" (Cooley 1997:11, citado por Pelinski 2000: 289).

Se pueden distinguir, desde esta perspectiva, dos cambios relevantes en la práctica etnomusicológica, que están completamente ligados con el desarrollo de las naciones, el acelerado avance tecnológico ligado a la informática, que produce un sistema de comunicación distinguido como "redes sociales" gracias a internet, y lo no menos importante que es el acceso a programas televisivos locales y de gran parte del mundo por TV cable. Mediante el contacto de la aldea con la urbe, nativos que antes éramos estudiados por europeos o 
estadounidenses, ahora somos profesionales universitarios, etnomusicólogos en nuestro caso, en que el Otro/Otra y su cultura, ahora soy yo misma la Otra/Otro y es mi propia cultura la que estudio. El otro cambio que podemos distinguir es la relación recíproca que establecemos con nuestros colaboradores. Se plantean vínculos de interculturalidad: ambos aprendemos, ambos enseñamos, es decir, compartimos saberes y experiencias, lo que permite una comprensión respetuosa que conlleva una divulgación ética, puesto que nuestro colaborador pasa a ser coautor del discurso musicológico elaborado en conjunto.

\section{Manuel Mamani: etnomusicolología andina intercultural-poscolonial}

En este homenaje a Manuel Mamani, mi estimado colega, es relevante develar y explicitar el enfoque que él ha podido darle al quehacer etnomusicológico. Nacido y criado como aymara en el altiplano andino chileno, desde pequeño mostró sus dotes musicales, lo que le llevó por senderos urbanos capitalinos para estudiar y perfeccionarse. Fue acogido por la Universidad de Chile sede Arica a su regreso, en su doble rol de estudiante y académico de la carrera de Pedagogía en Educación Musical y director del Conjunto de Proyección Folclórica de la Universidad. Siempre inquieto y estudioso, tiene un encuentro con María Ester Grebe y posteriormente, durante la primera mitad de los años ochenta se encuentra con Martha Hardman, lingüista-antropóloga experta en hakaru, la lengua madre del aymara, quien lo insta a estudiar en la Universidad de Florida en los Estados Unidos. Es entonces que sus investigaciones informales de toponimia y música andina/aymara las formaliza y sistematiza según los cánones académicos hegemónicos.

Pero esto es imposible al 100\%. El discurso etnomusicológico de Manuel interactúa en el formato académico con su propio ser aymara. Por lo tanto expone en forma natural lo emic, cambia el sentido de la "alteridad", pues él mismo es el Otro. Esto se puede apreciar en sus dos artículos publicados en la Revista Musical Chilena. Uno de ellos se encuentra en la Revista No 198 del año 2002, titulado "El rito agrícola de Pachallampi y la música en Pachama, precordillera en Parinacota". El otro se encuentra en la Revista No 213 del año 2010, titulado "Kirkir Warmi: identidad y rol de la mujer aymara en el desarrollo musical del norte chileno". El primero es etnográfico musical, describe el ritual-ceremonial, su significado, las relaciones con las divinidades, los roles de los participantes y los aspectos relacionados con lo musical. En el segundo artículo hace una reseña etnohistórica basada en una bibliografía que ilustra la participación de la mujer andina quechua y aymara en la propia cultura. Pone énfasis en la dualidad y reciprocidad en relación con el hombre, como una manera de fundamentar el tipo de práctica musical que la mujer ejerce en estos últimos tiempos en el mundo andino chileno. Ambos artículos exponen, entre líneas y en ocasiones explícitamente, las propias vivencias del autor. Describe lo observado en el trabajo de campo trayendo a colación la propia historia de vida y cosmovisión que va de la mano con su lengua madre, el aymara, para sistematizar así una comprensión aprehendida del asunto en estudio.

\section{La Revista Musical Chilena}

La Revista Musical Chilena fue creada el año 1945, bajo el alero del Instituto de Extensión Musical perteneciente a la Facultad de Ciencias y Artes Musicales de la Universidad de Chile, con el propósito de servir de expresión a los estudiosos del país y a "los críticos y estudiosos americanos y europeos con residencia en este continente" (Santa Cruz 1945:2). Después de treinta años este planteamiento fue reafirmado por su nuevo Director, el Dr. Luis Merino Montero, con el agregado que "su núcleo debe estar constituido por trabajos que se ajusten a las categorías de objetividad, rigor científico, originalidad, claridad y consistencia en la 
presentación, y que en su sustancia conformen una 'fisonomía ante todo americanista' (Merino 1975: 13-14). Desde el $\mathrm{N}^{\circ} 1$ se pueden encontrar artículos relativos al folclore musical y la etnomusicología, varios de ellos escritos por connotados investigadores europeos, estadounidenses, latinoamericanos y chilenos como Erich von Hornbostel, George List, Francisco Curt Lange, Isabel Aretz, Carlos Lavín, Carlos Isamitt, Manuel Dannemann, Raquel Barros, María Ester Grebe, entre otros. Las temáticas abordadas en esta línea abarcan estudios acerca de músicas de culturas africanas, árabes, latinoamericanas y chilenas. Entre estas últimas figuran trabajos relativos a culturas originarias, prácticas del folclore criollo, religiosidad popular mariana y organología. En estas últimas décadas surgen temáticas que abordan el estudio de la música popular urbana.

Gracias a la ininterrumpida circulación de la Revista, junto a la conservación de la rigurosidad en lo formal y los contenidos de los artículos musicológicos y etnomusicológicos, la Revista Musical Chilena ha contado con el apoyo del Fondo Universitario de las Artes (FUAR), la Comisión Nacional de Investigación Científica y Tecnológica (CONICYT) y la Sociedad Chilena del Derecho de Autor (SCD). Esto le ha servido de respaldo para su indexación en ScIELO (Scientific Electronic Library Online) producida el año 1996 y su indexación en ISI (Institute for Scientific Information), actual Thomson Routers-Web of Science el año 2007. Por similares razones, la Academia Chilena de Bellas Artes del Instituto Chile distinguió a la Revista con el Premio "Academia” un 18 de octubre de 1999.

Esto implicó a la dirección de la Revista, a cargo del Dr. Luis Merino y al Subdirector Fernando García, crear un Comité Editorial, el que fue implementado el año 1994. La Revista $\mathrm{N}^{\circ} 182$ fue la primera en ser publicada bajo el alero de un Comité Editorial. Este primer Comité estuvo integrado por Miguel Aguilar Ahumada, Miguel Castillo Didier, Gabriel Matthey Correa, Rodrigo Torres Alvarado y quien suscribe. El año 1998 se estableció un Comité de Honor, integrado por destacados compositores y musicólogos, los chilenos Miguel Aguilar Ahumada, Gustavo Becerra Schmidt y Juan Orrego Salas, además del estadounidense Robert Stevenson, muy ligado a la formación de musicólogos chilenos y latinoamericanos.

\section{Manuel Mamani integra el Comité Editorial de la RMCh}

En este marco aparece la figura de Manuel Mamani Mamani. El año 1998 es invitado por la dirección de la Revista a integrar el Comité Editorial, en el que permaneció hasta el año 2009, un período que abarcó desde la Revista LIII/192 (julio-diciembre, 1999) hasta la LXIII/212 (julio-diciembre, 2009). Durante esa época asistió casi regularmente a las sesiones del Comité, realizadas semestralmente, por lo general en enero y julio de cada año. Siempre llegó con informes escritos de las evaluaciones encomendadas, y cuando no asistió por alguna eventualidad de viaje o salud, enviaba sus informes para ser leídos por el Subdirector. Recuerdo que sus indicaciones y comentarios eran precisos, ajustados a la pauta entregada por el Director de la Revista. Sus recomendaciones de publicar o no un artículo eran claramente fundamentadas, al igual que las acotaciones verbales que hacía ante una discusión entre los miembros del Comité sobre alguna evaluación, debido a criterios diferentes a los suyos.

$\mathrm{Su}$ prestigioso trabajo académico enfocado en la música, la proyección folclórica además de la investigación toponímica y etnomusicológica andina chilena, le valieron su integración al Comité de Honor de la Revista Musical Chilena. Han sido sus pares Gustavo Becerra Schmidt y Robert Stevenson, ya fallecidos, junto a los actuales Miguel Aguilar Ahumada, compositor y musicólogo, Premio Presidente de la República 2006; Fernando García Arancibia, compositor y musicólogo, Premio Nacional de Artes Musicales 2002, y Juan Orrego Salas, compositor y musicólogo, Premio Nacional de Artes Musicales 1992. 


\section{BIBLIOGRAFÍA}

Barrientos Pacheco, Lina

1995-2014 Cuaderno bitácora del Comité Editorial, desde el 9 de junio de 1995 hasta el 1 de julio de 2014 (manuscrito).

2013 Etnomusicología. Breve reseña historiográfica para el curso de musicología. Apuntes de clase, Universidad de La Serena, 4 pp.

Guerra Rojas, Cristián

2014 "La Revista Musical Chilena en el siglo XXI: índices temáticos electrónicos en su sitio Web”. Ponencia presentada en el V Simposio Internacional de Musicología de la Universidad Federal de Rio de Janeiro (UFRJ), "Periódicos musicales: historia, crítica y políticas editoriales”, 11-15 de agosto.

Mamani Mamani, Manuel

2002 "El rito agrícola del Pachallampi y la música en Pachama, precordillera de Parinacota", RMCh, LVI/198 (julio-diciembre), pp. 45-62.

2010 "Kirkir Warmi: identidad y rol de la mujer aymara en el desarrollo musical del norte chileno", RMCh, LXIV/213 (enero-junio), pp. 90-102.

Maturana, Humberto y Gerda Verden Zöller

2003 Amor y juego. Fundamentos olvidados de lo humano. JC Záez (editor). Santiago: Editorial LOM.

Merino Montero, Luis

1975 "Reflexiones", RMCh, XXIX/129-130 (enero-junio), pp. 13-15.

2012 “In memoriam. María Ester Grebe Vicuña (1928-2012)”, RMCh, LXIV/218 (juliodiciembre), p. 96 .

Myers, Helen

2001 "Etnomusicología", en Francisco Cruces y otros (editores). Las culturas musicales. Lecturas de etnomusicología. Madrid: SIbE-Sociedad de Etnomusicología, Editorial Trotta, pp. 19-39.

Pelinski, RAMón

2000 Invitación a la etnomusicología. Quince fragmentos y un tango. Madrid: Editorial Akal, capítulo XV: "Etnomusicología en la edad posmoderna", pp. 282-296.

Revista Musical Chilena Revisadas

1945 I/1 (mayo)

$1955 \mathrm{X} / 50$ (julio)

1966 XX/98 (octubre-diciembre)

1994 XLVIII/182 (julio-diciembre)

1996 L/186 (julio-diciembre)

1998 LII/190 (julio-diciembre)

1999 LIII/192 (julio-diciembre)

2007 LI/207 (enero-junio) 
2010 LIV/213 (enero-junio)

2013 LVII/220 (julio-diciembre)

Santa Cruz, Domingo (s/firma)

1945 “Nuestro propósito", RMCh, I/1 (mayo, 1945), pp. 1-3. 